\title{
Review
}

Others

Diabetes Metab J 2019;43:383-397

https://doi.org/10.4093/dmj.2019.0121

pISSN 2233-6079 · eISSN 2233-6087

DIABET\&S \& METABOLISM JOURNAL

\section{Continuous Glucose Monitoring Sensors for Diabetes Management: A Review of Technologies and Applications}

\author{
Giacomo Cappon, Martina Vettoretti, Giovanni Sparacino, Andrea Facchinetti \\ Department of Information Engineering, University of Padova, Padova, Italy
}

\begin{abstract}
By providing blood glucose (BG) concentration measurements in an almost continuous-time fashion for several consecutive days, wearable minimally-invasive continuous glucose monitoring (CGM) sensors are revolutionizing diabetes management, and are becoming an increasingly adopted technology especially for diabetic individuals requiring insulin administrations. Indeed, by providing glucose real-time insights of BG dynamics and trend, and being equipped with visual and acoustic alarms for hypoand hyperglycemia, CGM devices have been proved to improve safety and effectiveness of diabetes therapy, reduce hypoglycemia incidence and duration, and decrease glycemic variability. Furthermore, the real-time availability of BG values has been stimulating the realization of new tools to provide patients with decision support to improve insulin dosage tuning and infusion. The aim of this paper is to offer an overview of current literature and future possible developments regarding CGM technologies and applications. In particular, first, we outline the technological evolution of CGM devices through the last 20 years. Then, we discuss about the current use of CGM sensors from patients affected by diabetes, and, we report some works proving the beneficial impact provided by the adoption of CGM. Finally, we review some recent advanced applications for diabetes treatment based on CGM sensors.
\end{abstract}

Keywords: Blood glucose self-monitoring; Diabetes mellitus; Hyperglycemia; Hypoglycemia; Insulin infusion systems

\section{INTRODUCTION}

Among the many glucose-sensing mechanisms tested to guarantee all the necessary requirements for long-term use of biosensor in free-living conditions, i.e., biocompatibility, lifetime, safety, sensitivity, and specificity, the most popular technique used for continuous glucose monitoring (CGM) systems relies on the glucose oxidation reaction [1]. Specifically, CGM devices based on this principle use a glucose-oxidase-doped platinum electrode deposited on a needle inserted in the subcutaneous tissue to ignite and catalyze glucose oxidation. This results in the production of gluconolactone, hydrogen peroxide, and an electrical current signal that is transformed, in the end, to a glucose concentration through a calibration process using a few self-monitoring of blood glucose (SMBG) samples collected by the patient [2].

The introduction of these "minimally invasive" needle CGM sensors in 1999 [3] revolutionized, de facto, blood glucose (BG) concentration monitoring in diabetes and opened new exciting scenarios in the daily management of diabetes [4]. CGM sensors deliver an almost continuous glucose trace providing BG readings every 1 to 5 minutes, mitigating the need of SMBG and greatly increasing the information on BG fluctuations and trend (which shows that CGM reveals hypoglycemic and hyperglycemic events not visible by SMBG) (Fig. 1A). Since the first prototype, CGM sensors have evolved remarkably. Nowa-
Corresponding author: Andrea Facchinetti (iD https://orcid.org/0000-0001-8041-2280 Department of Information Engineering, University of Padova, Via Gradenigo 6/B, Padova 35131, Italy

E-mail: facchine@dei.unipd.it

Received: Jun. 17, 2019; Accepted: Jul. 10, 2019
This is an Open Access article distributed under the terms of the Creative Commons Attribution Non-Commercial License (http://creativecommons.org/licenses/by-nc/4.0/) which permits unrestricted non-commercial use, distribution, and reproduction in any medium, provided the original work is properly cited. 
days, they are also able to provide patients with many smart features, such as arrows depicting the current glucose rate-ofchange and smart alarms for impeding hypo-/hyperglycemic events, improving patient self-management. Although, mainly due to economic cost and patient acceptability of sensor devices, CGM users represent only a small part of total diabetes population, CGM sensors proved to be effective in improving patient glucose control [5-7] and enabling the possibility of designing new advanced technologies for diabetes management $[8,9]$.

The purpose of this paper is to (1) provide an overview of the latest advances on CGM system development and glucose sensing technologies, (2) discuss about the current use of CGM sensor from patient affected by diabetes, and (3) review some recent advanced applications for diabetes treatment based on CGM. To do so, based on our experience as researchers active in the diabetes technology field, we will focus on the current literature works that we think are able to provide a general overview on the many undergoing activities involving CGM.

\section{HISTORY OF CGM SENSORS}

\section{The first CGM prototypes}

CGM devices based on glucose-oxidase have been proposed starting from the 1999, when the U.S. Food and Drug Administration (FDA) approved the first professional CGM system to be used by healthcare professionals, thus enabling the possibili- ty of analyzing retrospective user data for review [3]. This system, however, suffered from several limitations, the most important of which was poor accuracy, i.e., a concept quantifiable through some metrics. This system, however, suffered from several limitations, the most important of which was poor accuracy, which is usually assessed by comparing the CGM trace with very accurate and precise BG concentration values, commonly collected in a hospital setting by mean of laboratorygrade medical instruments, i.e., Yellow Spring Instruments Inc. (YSI, Yellow Spring, OH, USA) (Fig. 1B). Several metrics can be computed over these differences, such as \%20/20-ISO boundaries, absolute relative difference, and mean absolute relative difference (MARD) [10]. Among these quantities, MARD is the most common metric currently used in the literature to assess CGM accuracy [11], and the one on which we will focus hereafter. In 2004, Medtronic (Medtronic Minimed, Northridge, CA, USA) introduced and successfully commercialized the first real-time CGM system for personal use: the Medtronic Real-Time Guardian. This system provided patients with a glucose concentration value every 5 minutes, lasted 3 days, and it was able to sound an alarm when the glucose concentration level became either too high or too low, helping users to improve glucose control. The Medtronic Real-Time Guardian's MARD was estimated to be $15 \%$. Dexcom Inc. (San Diego, CA, USA) commercialized the Dexcom SEVEN Plus, which had longer lifetime, lasting up to 7 consecutive days. The accuracy of the Dexcon SEVEN Plus was 16.7\% [12], slightly worst of that of the Medtronic Real-Time Guardian, but significantly
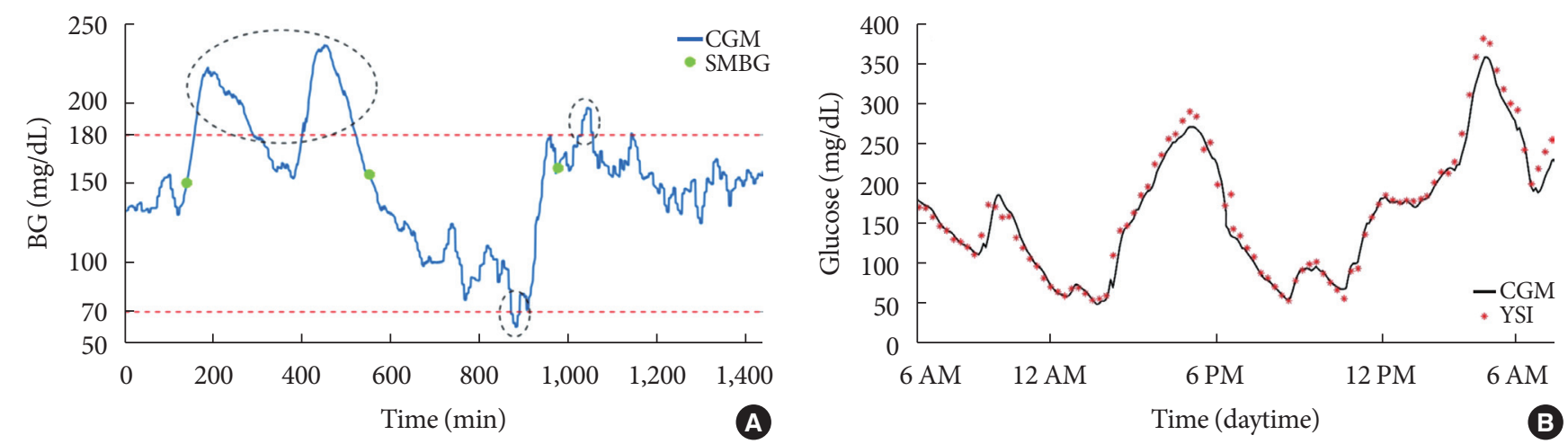

Fig. 1. (A) Representative blood glucose (BG) monitoring data obtainable with self-monitoring of blood glucose (SMBG; in green) and with continuous glucose monitoring (CGM; in blue). Dotted circles denote hyperglycemic and hypoglycemic episodes that, using only SMBG measurements, are not detectable. (B) Assessment of the accuracy of a CGM sensor can be performed by comparing Yellow Spring Instruments Inc. (YSI) measurements (red stars) versus Dexcom G4 Platinum CGM (black solid line) measurements. For example, mean absolute relative difference can be calculated as the average ratio between the absolute difference between the CGM measurements and the YSI over the YSI. 
better than that of its predecessor. The same year, the Abbott Freestyle Navigator (Abbott Diabetes Care, Alameda, CA, USA) was marketed, featuring a glucose sensor that could be worn up to 5 days and achieving an MARD of $12.8 \%$ [13]. Compared to SMBG, whose MARD falls between $5 \%$ and $10 \%$, the low accuracy (i.e., elevated MARD) of these "first generation" CGM systems represented one of the major barrier for the early adoption of these devices by both users, who felt unsafe in adopting CGM, and many leading diabetologists, whose reluctance to integrate CGM sensors in the daily diabetes management greatly limited the spreading of this technology.

\section{The most recent CGM systems}

In the last decade, CGM manufacturers invested many efforts to overcome the problems of lack of accuracy of their first generation devices. The first new generation product was the Medtronic Enlite CGM system. This device, besides achieving a MARD of 13.6\% [14], extended the wear time up to 6 days. In addition, it improved the sensor comfortability by reducing its size and weight, it was designed to be water-proof, and it allowed the memorization of BG up to 10 hours if the receivertransmitter connection is interrupted for any reasons. The same year, Abbott launched the Freestyle Navigator II, a newly designed CGM system that provided BG readings every minute with a 12.3\% MARD [15]. In 2012, Dexcom introduced the G4 Platinum, featuring a smaller sensor, lasting for 7 days, and reducing the MARD to 13\% [16], later improved to 9\% in 2014 thanks to new algorithms integrated directly within the sensor [17]. In 2015, Dexcom introduced the G5 Mobile [17] achieving a MARD of 9\%, a 7 days wear time, now allowing BG data to be directly transmitted to the user's cell phone without the need of a dedicated receiver.

Later on, in 2016, Abbott commercialized the Freestyle Libre featuring a MARD of $11.4 \%$ [18]. This CGM system is the first that required no fingerstick testing during wear. In addition, it extended the wear time up to 14 days. Unlike Dexcom or Medtronic CGM devices, the Freestyle Libre does not sound any alarms if BG falls out of the safe glycemic range and it requires patient to wave the receiver over the transmitter in order to get BG information, and to do so at least one time every 8 hours in order not to lose data. For this reason, the Freestyle Libre is labelled as a flash glucose monitoring (FGM) device, i.e., a device that measures $B G$ at continuous time but displays the measured values only when scanning the sensor with the receiver. The Freestyle Libre has been the first glucose moni- toring device that required no calibrations, with the additional advantage of performing similarly in terms of both accuracy and BG control compared to CGM devices that require two or more calibrations per day, e.g., the G4 Platinum and the Freestyle Navigator II [19]. Following this technological trend, Dexcom launched in 2017 the G6 [20], a CGM system that can be used without in vivo calibrations, for 10 consecutive days, ensuring the same accuracy of the G5 Mobile. In the same year, Medtronic introduced the Guardian Sensor 3, whose accuracy was quantified as $10.6 \%$ and 9.1\% MARD [21], when inserted in the abdomen and in the arm, respectively. This sensor is $80 \%$ smaller than the Enlite, and it ensures up to 7 days of sensor life as well as a shorter startup time.

To summarize, in the last decade, besides achieving accuracies close to, or even within, the SMBG accuracy range, CGM systems improved also in terms of features and comfort for the patient. In Fig. 2 we reported a graphical representation of the CGM system accuracy evolution through years. In Table 1, we summarized the main characteristics in terms of accuracy, features, and limitations of the most known CGM sensor devices.

\section{Technological challenges of next generation CGM sensors}

CGM systems are now accepted as standard tools for intensive glucose control in patients with type 1 diabetes mellitus (T1DM). However, several important limitations are still present. Indeed, glucose-oxidase based electrochemical sensors suffer from several limits such as their non-linear response within the biological relevant range, the possible interference with active agents

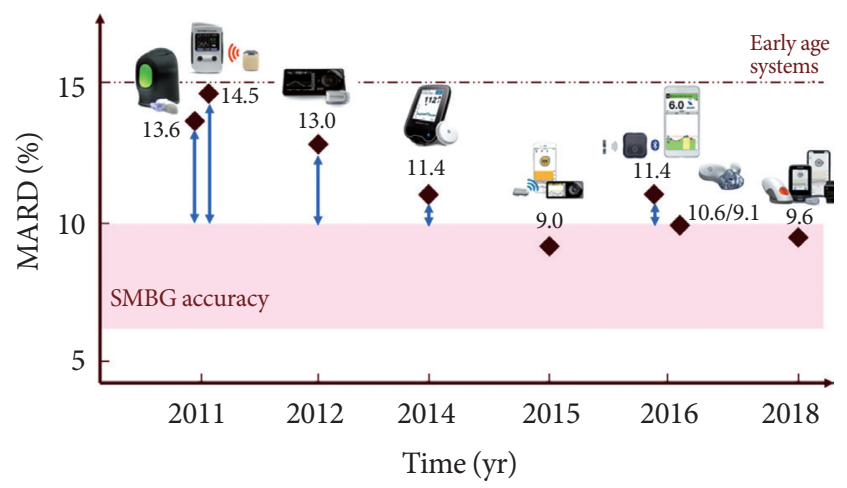

Fig. 2. Accuracy evolution of state-of-the-art CGM systems through years. From the left: Medtronic Enlite, Abbott Freestyle Navigator, Dexcom G4 Platinum, Abbott Freestyle Libre, Dexcom G4 Platinum with 505 software, Senseonics Eversense, Dexcom G5, Dexcom G6. MARD, mean absolute relative difference; SMBG, self-monitoring of blood glucose. 
Table 1. Summary of the main characteristics in terms of accuracy, features, and limitations of state-of-the-art CGM sensor devices

\begin{tabular}{|c|c|c|c|c|c|c|}
\hline Manufacturer & $\begin{array}{c}\text { CGM } \\
\text { system }\end{array}$ & $\begin{array}{l}\text { Accuracy } \\
\text { (MARD), \% }\end{array}$ & Calibrations & $\begin{array}{l}\text { Sensor } \\
\text { lifetime, } \\
\text { day }\end{array}$ & Smart features & Main limitations \\
\hline \multirow[t]{2}{*}{ Medtronic } & Enlite Sensor & 13.6 & Every $12 \mathrm{hr}$ & 6 & $\begin{array}{l}\text { Trend arrows, rate-of-change } \\
\text { alerts, hypo/hyperglycemic } \\
\text { alarms, integration with } \\
\text { Medtronic's pumps }\end{array}$ & $\begin{array}{l}\text { Approved only for as an adjunctive } \\
\text { device, acetaminophen interference }\end{array}$ \\
\hline & $\begin{array}{l}\text { Guardian } \\
\text { Sensor } 3\end{array}$ & $\begin{array}{l}10.6 \text { (abdomen) } \\
9.1 \text { (arm) }\end{array}$ & Every $12 \mathrm{hr}$ & 7 & $\begin{array}{l}\text { Trend arrows, rate-of-change } \\
\text { alerts, hypo/hyperglycemic } \\
\text { alarms, integration with } \\
\text { Medtronic's pumps }\end{array}$ & $\begin{array}{l}\text { Approved only for as an adjunctive } \\
\text { device, acetaminophen interference }\end{array}$ \\
\hline \multirow[t]{3}{*}{ Abbott } & $\begin{array}{l}\text { Freestyle } \\
\text { Navigator II }\end{array}$ & 14.5 & $\begin{array}{l}2,10,24, \\
72 \mathrm{hr} \text { after } \\
\text { insertion }\end{array}$ & 5 & $\begin{array}{l}\text { Trend arrows, rate-of-change } \\
\text { alerts, hypo/hyperglycemic } \\
\text { alarms }\end{array}$ & $\begin{array}{l}\text { Approved only in some European } \\
\text { countries as adjunctive device }\end{array}$ \\
\hline & $\begin{array}{l}\text { Freestyle } \\
\text { Libre }\end{array}$ & 11.4 & No & 14 & Trend arrows & $\begin{array}{l}\text { Sensor need to be scanned to get a } \\
\text { glucose reading, not recommended } \\
\text { for patient with hypoglycemic } \\
\text { unawareness, confirmatory SMBG } \\
\text { still recommended when specific } \\
\text { episodes occur }\end{array}$ \\
\hline & $\begin{array}{c}\text { Freestyle } \\
\text { Libre } 2\end{array}$ & Not available & No & 14 & $\begin{array}{l}\text { Trend arrows, rate-of-change } \\
\text { alerts, hypo/hyperglycemic } \\
\text { alarms, remote monitoring }\end{array}$ & $\begin{array}{l}\text { Sensor need to be scanned to get a } \\
\text { glucose reading, not recommended } \\
\text { for patient with hypoglycemic } \\
\text { unawareness, confirmatory SMBG } \\
\text { still recommended when specific } \\
\text { episodes occur }\end{array}$ \\
\hline \multirow[t]{3}{*}{ Dexcom } & G4 Platinum & 9 & Every $12 \mathrm{hr}$ & 7 & $\begin{array}{l}\text { Trend arrows, rate-of-change } \\
\text { alerts, hypo/hyperglycemic } \\
\text { alarms, remote monitoring }\end{array}$ & $\begin{array}{l}\text { Approved only as an adjunctive } \\
\text { device }\end{array}$ \\
\hline & G5 Mobile & 9 & Every $12 \mathrm{hr}$ & 7 & $\begin{array}{l}\text { Trend arrows, rate-of-change } \\
\text { alerts, hypo/hyperglycemic } \\
\text { alarms, remote monitoring, } \\
\text { wireless communication with } \\
\text { up to } 5 \text { devices }\end{array}$ & $\begin{array}{l}\text { Confirmatory SMBG still recom- } \\
\text { mended when specific episodes } \\
\text { occur, acetaminophen interference }\end{array}$ \\
\hline & G6 & 10 & No & 10 & $\begin{array}{l}\text { Trend arrows, rate-of-change } \\
\text { alerts, hypo/hyperglycemic } \\
\text { alarms, remote monitoring, } \\
\text { wireless communication with } \\
\text { up to } 5 \text { devices }\end{array}$ & $\begin{array}{l}\text { Confirmatory SMBG still recom- } \\
\text { mended when specific episodes } \\
\text { occur }\end{array}$ \\
\hline Senseonics & Eversense & 11.4 & No & 90 & $\begin{array}{l}\text { Trend arrows, rate-of-change } \\
\text { alerts, hypo/hyperglycemic } \\
\text { alarms }\end{array}$ & $\begin{array}{l}\text { The sensor needs to be inserted and } \\
\text { removed in doctor's office, approved } \\
\text { as adjunctive device in Europe only }\end{array}$ \\
\hline
\end{tabular}

CGM, continuous glucose monitoring; MARD, mean absolute relative difference; SMBG, self-monitoring of blood glucose.

(e.g., acetaminophen, ascorbate), and most importantly, their dependence of both sensitivity and specificity on the enzyme availability on the electrode surface. Moreover, BG readings provided by glucose-oxidase based CGM sensors are affected by delay artifacts, which range from 5 to 10 minutes, due to the time lag between glucose concentration in the interstitial fluid and BG. On one hand, delay is not important when analyzing retrospective glucose data, on the other, it can be critical when CGM is used for real-time decision making.

For this reason, further research is currently undergoing to 
address previously listed issues and designing new CGM sensors able to better meet technological requirements such as sensor size, lifetime, and capabilities.

From this perspective, in August 2015, Dexcom started a new collaboration with Verily (Verily Life Science LLC, San Francisco, CA, USA) to develop a new miniaturized, cheaper, patch CGM sensor designed to minimize its burden to the patient and to help people with type 2 diabetes mellitus (T2DM) managing their daily routine [22]. In 2018, Abbott released the Freestyle Libre 2, which successfully secured the Conformité Européene (CE) mark in October 2018, and improved the Libre by adding smart alarms [23].

Next generation CGM system development also involves the exploration of new glucose sensing technologies beyond glucose-oxidase. In this regard, glucose sensors based on optical sensing have been recently proposed. These sensors provide an interesting alternative to traditional electrochemical sensors since they have the benefit of being free from electromagnetic interference, simple to design and handling, and characterized by low manufacturing cost. These principles have been used to design non-invasive sensors based on near infrared detection and Raman spectroscopy [24], and fully implanted CGM systems based on fluorescence [25]. In 2016, Senseonics (Senseonics Inc., Germantown, MD, USA) launched the Eversense, the first implantable CGM system to receive the CE mark. As already mentioned, it is based on fluorescence sensing, featuring a lifetime of 90 days, and an accuracy of $11.4 \%$ MARD [26]. Of course, this approach is quite demanding for the patient, who is required to undergo a, even if simple, surgical procedure, but the sensor lifetime makes this system a good and appealing alternative.

Lastly, next generation CGM systems require guaranteeing data security. Indeed, being limited by low computing capabilities, CGM transmitters, and more in general wearable devices, have been proven to suffer from several security weaknesses that make user data relatively easy to potentially be hacked [27]. Even if, to the best of our knowledge, cyberattacks to CGM sensor devices have never been publicly reported yet, these potential security flaws need to be fixed to ensure data confidentiality and integration without undermining its availability. Recently, the Diabetes Technology Society established DTSec, i.e., a new consensus-based standard thought to provide a high security and assurance level among electronic devices used in diabetes treatment including, but not limited to, insulin pumps, SMBG devices, and, of course, CGM systems [28].

\section{CURRENT USE OF CGM TECHNOLOGIES}

\section{Professional use}

CGM sensors can be used as professional or personal devices. Professional CGM systems are owned by caregivers and intermittently prescribed to patients in blinded mode. Blinded CGM devices collect glucose concentration data continuously but do not display them in real-time to the user; data can only be reviewed retrospectively by the caregiver at the end of the monitoring. Blinded data collection allows tracking patients' glucose profiles without influencing their behavior. Examples of professional CGM devices for blinded data collection include the Abbott Freestyle Libre Pro system and the Medtronic iPro2 system. The retrospective analysis of CGM data allows the caregiver to extract glycemic variability metrics, identify previously unappreciated glucose patterns and adjust therapy regimens accordingly.

Glycemic variability represents how much BG fluctuates around the average value and is considered an important glycemic target, together with glycosylated hemoglobin (HbAlc), to reduce the risk of diabetes complications [29]. Notably, glycemic variability cannot be captured by sparse SMBG measurements, but it can be detected by CGM almost continuoustime profiles. Several CGM-based glycemic variability metrics have been proposed in the literature [30]. Recently an international panel of physicians, researchers and patients expert in CGM technologies defined the key metrics for CGM data analysis and reporting [31]. The panel also recommended the Ambulatory Glucose Profile (AGP) [32], a standardized single page report with summary statistics and daily glycemic patterns developed by the International Diabetes Center, as a standard for the visualization of CGM data. The AGP report has been included in many proprietary software for retrospective CGM data analysis, e.g., Dexcom CLARITY, DiasendGlooko, Tidepool, LibreView, and Medtronic CareLink.

\section{Personal use}

In addition to the retrospective data analysis, CGM systems for personal use allow the individual to visualize in real-time information on current BG and trend on a portable receiver or a smartphone application. Most of personal CGM systems currently on the market, including the Dexcom G5 Mobile and G6, the Medtronic Enlite and Guardian, and the Senseonics Eversense, provide high and low BG alerts that help the patient to detect hypo/hyperglycemic events. Alerts are not available 
with the FreeStyle Libre, which, despite considered a glucose sensor for personal use, falls within the category of FGM devices. Alerts have been introduced in a new generation FGM device, i.e., the FreeStyle Libre 2. Devices for personal use also allow data sharing with third parties, such as parents, partners and caregivers. The Dexcom G5 Mobile and G6 and the Eversense sensors can share the data in real-time, a feature that is very useful for the pediatric population, as parents are enabled to check remotely their children's BG during school, physical activity or sleep. The Freestyle Libre and the Medtronic Enlite and Guardian sensors can share the data, but not in real-time.

Until a few years ago, all CGM devices for personal use were approved to be used in adjunct to SMBG, i.e., before making the treatment decisions patients were required to check CGM readings by confirmatory fingersticks. Indeed, as described in Section "History of CGM Sensors," past CGM sensors suffered from accuracy problems due to plasma-interstitium kinetics, imperfect calibrations, compression artefacts and sensitivity to interfering substances, such as acetaminophen. Thanks to recent technological developments and enhancement of signal processing algorithms, the accuracy of CGM sensors has been remarkably improved during the last years, reaching the range of accuracy performance of SMBG devices (MARD $<10 \%$ ). These improvements led to the regulatory approval of CGM nonadjunctive use, i.e., the use of CGM readings to make treatment decisions without confirmatory fingersticks, whose safety and effectiveness have been proved by simulations [8] and a randomized non-inferiority clinical trial [33]. From 2014 to 2015, three CGM sensors received the nonadjunctive label in Europe: the FreeStyle Navigator II, the FreeStyle Libre and the Dexcom G5 Mobile. The approval of nonadjunctive use by the FDA came a couple of years later: the Dexcom G5 Mobile obtained the approval in 2016, followed by the FreeStyle Libre in 2017 and the Dexcom G6 in 2018. Despite the nonadjunctive label, sensor companies still recommend the use of confirmatory fingersticks when symptoms do not match sensor's readings or a trend arrow is not displayed. With the FreeStyle Libre, confirmatory fingersticks are also recommended when glucose is rapidly changing and in order to confirm hypoglycemia or impending hypoglycemia.

Real-time CGM sensors for personal use, in particular those approved for nonadjunctive use, can be used by the patients to make therapeutic decisions, e.g., insulin dosing. Compared to conventional SMBG devices, CGM also provides information on current glucose trend that can be exploited for a more accu- rate calculation of insulin boluses. Clinical experts in the field have proposed some guidelines that recommend the patient to increase or decrease the insulin dose by a certain amount (either proportional to the dose or inversely proportional to the patient's correction factor) when the CGM trend arrow indicates glucose concentration is rising or decreasing [34]. Nevertheless, these guidelines have never been assessed in clinical trials and survey data evidenced that patients actually perform much greater corrections to the insulin dose than those recommended by the guidelines [35]. A recent in silico study compared three different trend adjustment guidelines in simulation [36]; the results evidenced that none of the guidelines prevailed on the others for all the pre-meal scenarios, suggesting that these simple guidelines can be further improved.

\section{CGM uptake}

Historically CGM uptake was poor. From 2010 to 2012, only $7 \%$ of the T1D Exchange Registry participants were using CGM sensors [37]. A recent study reported that the most common barriers to CGM use were related to the high cost of the device, lack of insurance coverage, the hassle of wearing devices and the dislike of having devices on the body; the most common reasons for stopping CGM were cost, alarm fatigue and perceived sensor inaccuracy [38]. Nowadays, thanks to the recent developments in CGM technology, in particular the release of new more accurate sensors with reduced sensor size and calibration requirements, most of these barriers have been overcome. After the regulatory approval of CGM therapeutic use, the United States medical insurance company Medicare has announced reimbursement criteria for therapeutic CGM devices to all T1DM and T2DM patients on intensive insulin treatment [39]. Similarly, in many European countries CGM expenses are now covered by national healthcare systems, thus increasing the accessibility of such technology.

These changes has led to a growth of CGM use both in United States and in Europe. Most recent data from the T1D Exchange Registry reported that about $30 \%$ of participants have been using CGM in the period from 2016 to 2018 [40]. Abbott reported that about 800,000 people in 43 countries worldwide are currently using the FreeStyle Libre sensor [41]. In 2017, it was estimated that $18 \%$ of German/Austrian Diabetes Patienten Verlaufsdokumentation registry participants were using a CGM device [42]. Although the use of CGM sensors has increased, the CGM market is still moving slowly. Currently, only a small portion of well-trained T1DM individuals is using 
CGM, which represents less than $0.5 \%$ of the global diabetic population [43]. A possible reason for the low global uptake of CGM is that there are weak evidences that CGM is beneficial for T2DM patients not on intensive insulin treatment, which actually represent the majority of the diabetic population.

\section{To whom it is recommended}

Standards of diabetes care, like the American Diabetes Association and the American Association of Clinical Endocrinologists and American College of Endocrinology, recommend CGM use in conjunction with intensive insulin treatment for T1DM subjects who do not meet the glycemic target or suffer from hypoglycemia unawareness $[44,45]$. The Endocrine Society also recommends intermittent use of personal CGM devices for T2DM patients with poor glycemic control who are able and willing to use the device [46]. T2DM individuals were identified as possible beneficiaries of CGM use also by an international consensus on CGM, which recommended the use of CGM in conjunction with $\mathrm{HbA1c}$ to assess the glycemic status and adjust therapy regimen in all T1DM and T2DM patients on intensive insulin treatments [31]. Apart from T1DM and T2DM people on intensive insulin treatment, other groups may benefit from CGM use. For example, some studies have demonstrated that CGM use improves the neonatal outcomes when used in pregnant women with diabetes or gestational diabetes $[47,48]$.

\section{THE IMPACT OF CGM ON DAILY MANAGEMENT OF DIABETES}

Nowadays, the beneficial impact brought by the integration of a CGM system in diabetes management has been proven [49]. Indeed, initial reluctance from both clinicians and patients has diminished through years thanks to the constant accumulation of clinical evidence from research over adult and pediatric populations with T1DM [29]. Just to mention a few, recent research proved CGM sensors to be effective for patients with frequent hypoglycemic events [7], sensor augmented pumps [50], and gestational diabetes [47], treated with either continuous subcutaneous insulin infusion (CSII) or a multiple daily injection (MDI) insulin regimen. Published randomized controlled trials (RCTs) have been devoted to study the impact of CGM sensor systems on (1) improving glycemic control, (2) mitigating hypoglycemic episodes, (3) reducing glycemic variability. In the following, some significant literature results proving the beneficial impact of CGM are reported.

\section{Improvement of glycemic control}

Numerous RCTs have demonstrated improved glucose control in terms of reduced $\mathrm{HbAlc}$ in individuals using CGM compared to those using SMBG. Two major studies by Bergenstal et al. [51] and Juvenile Diabetes Research Foundation Continuous Glucose Monitoring Study Group et al. [5] considered T1DM individuals undergoing both MDI and CSII therapies and assessed the ability of several CGM sensors in improving the glucose control. In particular, both studies showed a significant reduction of $\mathrm{HbAlc}$ of $0.64 \%$ and $0.53 \%$, respectively, in subjects adopting CGM versus a control group employing standard therapy based on SMBGs. Moreover, both studies confirmed a direct relationship between sensor usage time and average $\mathrm{HbAlc}$ reduction. Specifically, Bergenstal et al. [51] showed that significant $\mathrm{HbA1c}$ reduction was possible only for users using CGM sensor between $41 \%$ and $60 \%$ of the time, which doubled in users who used CGM more than $80 \%$ of the time. Consistently, Juvenile Diabetes Research Foundation Continuous Glucose Monitoring Study Group et al. [5] reported that using CGM at least 6 days per week translate to an average reduction of $0.5 \%$ of $\mathrm{HbAlc}$. Similar conclusions have been reported in many other studies, spanning different population categories, e.g., from children to adult, from individuals affected by T1DM to women with gestational diabetes, elevating CGM as a particularly useful tool to achieve effective glucose control in diabetes.

\section{Mitigation of hypoglycemic episodes}

Reduction of hypoglycemia has been shown to be one of the major advantages provided by CGM use. Indeed, thanks to its intrinsically superior time resolution, CGM enables users to capture glycemic fluctuations that are invisible using SMBG only. The real-time availability of glucose concentration values as well as visual/acoustic hypoglycemic alerts allow users to act in order to mitigate, or even avoid, hypoglycemia.

In a recent multicenter clinical study involving T1DM subjects having good starting glucose control, a 50\% reduction of time spent in hypoglycemia has been shown, even if no significant reduction of $\mathrm{HbAlc}$ was reported [52]. Another study by Haak et al. [53] analyzed the impact of CGM use on individuals affected by T2DM in free-living conditions under either MDI or CSII therapy. Results showed a significant reduction of hypoglycemia of 53\%. However, no significant reduction of 
HbA1c has been observed although the study participants were poorly controlled T2DM subjects. The reason behind this result probably lies behind the lack of optimal education from the patients. To support this thesis, according to a recent study by Hermanns et al. [54], the usage of FGM was effective to reduce $\mathrm{HbAlc}$ in participants receiving proper structured education, but FGM itself without education was not effective in poorly controlled T1DM and T2DM under MDI therapy.

Summarizing, thanks to the adoption of CGM in diabetes treatment, hypoglycemia can be successfully mitigated both improving individuals' quality of life and reducing the shortcoming of dangerous short-term complications.

\section{Reduction of glycemic variability}

Several studies appear to confirm that glycemic variability can play a key-role in the appearance of vascular damages [29] and in the set-up of hypoglycemic events [55]. CGM sensors are important also in reducing glycemic variability in individuals affected by diabetes. In Jamiolkowska et al. [56], 40 subjects aged 14.6 years have been recruited to evaluate whether the use of CGM could improve glycemic variability in terms of glucose standard deviation (SD) and area under the curve (AUC). Results showed a reduction of SD from 60.7 to $51.7 \mathrm{mg} / \mathrm{dL}$ as well as a decreasing of AUC with threshold fixed at $140 \mathrm{mg} / \mathrm{dL}$ from $41.2 \%$ of the control group to $21.2 \%$ of the group that accepted the adoption of CGM use. Another study from Tumminia et al. [57] compared 10 individuals with T1DM undergoing MDI therapy. Participants were monitored for 6 months while being randomized into two groups to compare SMBG versus CGM in terms of SD of the glucose profile and range of glycemic excursions (RGEs). Results showed a reduction of both SD and RGE when using CGM compared to SMBG (62.3 $\mathrm{mg} / \mathrm{dL}$ vs. $75.5 \mathrm{mg} / \mathrm{dL}$ and $132.3 \mathrm{mg} / \mathrm{dL}$ vs. $175.3 \mathrm{mg} / \mathrm{dL}$, respectively).

In summary, the use of CGM was shown to be crucial to allow people affected by diabetes reducing glycemic variability. As a result, this unlocks the possibility of mitigating the shortcoming of both hypo and hyperglycemia as well as dangerous micro/macrovascular complications.

\section{ADVANCED APPLICATIONS BASED ON REAL-TIME CGM}

\section{Decision support systems}

The increased amount of available information brought by wearable devices, such as CGM systems and physical activity monitoring bands, has led to the development of decisionmaking tools and applications that can enhance the management of the disease [58]. A decision support system (DSS) gives the possibility to support users with proactive and personalized decisions in any scenario of their daily living and allows to react at shorter time scales. Over the past few years, DSSs for diabetes have been an emerging concept in health care. By means of this new technology, data can be automatically collected, transmitted, aggregated with other physiological data, analyzed, stored, and presented to the patient. By integrating e-health and tele-monitoring systems, DSSs for T1DM have the potential to improve glycemic outcomes thanks to prevention of hypo- or hyperglycemic events, reducing uncertainty when making critical self-management decisions [59]. A DSS for diabetes treatment provides an alternative to the closed-loop system, the so-called artificial pancreas (AP). Indeed, a wide range of users do not feel confident with the use of AP systems, being concerned about errors occurring in the insulin pump, and they prefer an open-loop therapy, which can be assisted by DSSs. Most of DSSs already available in the literature are composed by a predictive glucose module (which alerts the user whenever its BG is predicted to fall outside the safe range in the next future), an insulin suspension module (which temporarily suspends basal insulin delivery to avoid hypoglycemia when BG is critically low in patient using insulin pumps), and an adaptive insulin bolus calculator (which provides users with a suggestion of the correct insulin dosage to compensate the BG fluctuation due to a meal).

Many literature studies showed that DSSs are viable tools for improving diabetes treatment. A prototype bolus calculator algorithm based on neural networks providing personalized insulin recommendations has been developed and preliminarily tested in silico by Cappon et al. [60]. Breton et al. [61] proposed a DSS with automated insulin titration and dosing, proving that the use of the system results in reduced glucose variability and improved protection against hypoglycemia. Moreover, DreaMed (DreaMed Diabetes Ltd., Petah Tikva, Israel) recently introduced the Advisor Pro, a responsive application that provides real-time automated analysis of patient specific behavior to come up with personalized estimates of the optimal insulin treatment plan [62], which received FDA approval to be marketed in the United States in 2018 [63]. Finally, Patient Empowerment through Predictive PERsonalised decision support (PEPPER), a project funded by the European Community 
under the Horizon 2020 research program, has recently entered its final test phase, after several preliminary studies showed that it is able to improve glucose control and reducing the incidence of hypoglycemic episodes [64].

\section{Basal insulin attenuation/suspension}

Since 2006, medical devices integrating CGM sensors and insulin pumps have become commercially available, the Medtronic MiniMed Paradigm REAL-time system being the first device allowing such integration. Later in 2009, Medtronic integrated systems have been equipped with the low glucose suspend (or threshold suspend) feature that allows to automatically suspend basal insulin infusion for up to 2 hours when CGM measurements fall below a user-defined low glucose threshold. This feature, implemented in the Medtronic Paradigm Veo and MiniMed 530G, was designed to mitigate hypoglycemic events in insulin pump therapy [65]. Most recent Medtronic systems, i.e., the MiniMed 640G and 630G, implement the SmartGuard feature, which also allows to suspend basal insulin infusion when CGM measurements are predicted to fall below a preset threshold in the next 30 minutes (prediction low glucose management) [66].

Basal insulin suspension algorithms have been intensively studied also by academic research groups. In particular, the group led by Dr. Bruce Buckingham have been very active in this research line since 2009, by testing several prediction algorithms and insulin suspension criteria in both inpatient and outpatient clinical trials. Their final algorithm performs 30-minute ahead glucose prediction by a Kalman filter and suspends basal insulin when the predicted glucose concentration fall below $80 \mathrm{mg} / \mathrm{dL}$ [67]. Basal insulin delivery is restarted as soon as CGM measurements start rising or after 2 consecutive hours of suspension.

The algorithms developed by Buckingham et al. [67], as well as those implemented in commercial devices, can only turn on or off basal insulin delivery. A different approach was adopted by the group led by Prof. Kovatchev at the University of Virginia, who proposed algorithms to attenuate, rather than suspend, basal insulin delivery in presence of hypoglycemia risk. Specifically, their "power brakes" algorithm performs 15-minute ahead glucose prediction using physiological model-based Kalman filtering and applies a BG risk function in order to calculate a basal insulin attenuation factor depending on predicted risk of hypoglycemia [68].

Several clinical trials were performed to assess the safety and effectiveness of basal insulin suspension algorithms both in clinic under controlled conditions [69-72] and at home under real-life conditions [67,73-75]. Evidences from these trials supported the effectiveness of these algorithms in reducing hypoglycemia, at the expenses of a slight increase in hyperglycemia. Nevertheless, the use of basal insulin suspension was not associated with a significant increase of HbAlc or occurrence of ketoacidosis.

For an exhaustive review of algorithms for basal insulin suspension/attenuation, their implementation in commercial devices and clinical evidence of their effectiveness and safety, we refer the reader to [76].

\section{Closed-loop systems}

Automatic CGM-based basal insulin suspension/attenuation represents the first step towards closed-loop systems, namely AP, in which a control algorithm automatically tune insulin pump injections based on CGM readings. Research on closedloop systems has been very intense in the last 10 years [77-79]. Several control algorithms were proposed and assessed in clinical trials, including proportional-integral-derivative controller [80,81], model predictive control [82], and fuzzy logic controller [83]. Most of closed-loop systems adopt the hybrid approach, in which insulin boluses are manually administered by the user (meal amount required for meal bolus computation), while basal insulin rate is automatically tuned by the control algorithm. Recently, a hybrid closed-loop system has entered the market, as in 2017 Medtronic launched the MiniMed 670G, i.e., the first commercially available hybrid closed-loop system. A retrospective analysis of 3-month real-world glucose data has shown improved clinical outcomes in patients using the Auto Mode of the MiniMed 670G, compared to patients on Manual Mode [84]. Fully closed-loop systems that do not require patients to announce meals to the controller are also under development, though an increased risk for hypoglycemia has been reported in T1DM individuals with fully closed-loop control compared to hybrid closed-loop control [85]. A fully-closed loop system has been recently tested in adult inpatients with T2DM receiving non-critical care $[86,87]$. Results demonstrated that the closed-loop insulin delivery can greatly improve the time spent in the target range (difference between closed-loop and control groups of up to $32 \%$ points) without increasing hypoglycemia. A recent pilot study suggested that hybrid AP can be beneficial also for non-hospitalized MDI-treated T2DM subjects [88], although further investigation is needed to evalu- 
ate the cost-effectiveness of AP in this population.

While research in AP is progressively increasing the safety and effectiveness of such devices, also exploring bi-hormonal systems allowing controlled delivery of both insulin and glucagon [89], patients have shown an increased interest for the AP technology. This gave rise to the OpenAPS community, a community of patients highly interested in directly improving diabetes technologies, who have designed their own open source AP system, also called do-it-yourself closed-loop system. Although no clinical trial has ever assessed the safety and effectiveness of such open source systems, OpenAPS users self-reported an improvement in $\mathrm{HbA1c}$, time in range, glycemic variability and quality of life, while perceiving the OpenAPS system as safe $[90,91]$.

For an exhaustive review of algorithms for closed-loop control and AP technologies, we refer the reader to recent reviews [77-79].

\section{FUTURE PERSPECTIVES}

The advent of CGM sensors has revolutionized the glucose monitoring in T1DM. The recent approval of CGM therapeutic use and the new reimbursement policies have contributed to increase the number of CGM users worldwide, which is expected to further rise in the next years when less obtrusive and cheaper sensors will become available. Indeed, major CGM companies, like Dexcom and Medtronic, have announced the development of new products designed to be smaller and less expensive than current state-of-the-art systems, which can target not only T1DM patients, but also the much larger market of people with T2DM [22,92]. Furthermore, emerging companies are working on low-cost non-invasive CGM systems [93, 94], which may even bring CGM technology to the consumer market.

Important advances are expected also in terms of CGM interoperability with other devices, e.g., medical devices for diabetes therapy, activity trackers and other physiological wearable sensors. Indeed, the FDA has recently defined a new class of CGM devices, i.e., integrated continuous glucose monitoring (iCGM) systems, including devices to be used as part of an integrated system with other compatible medical devices and electronic interfaces. This will enable iCGM developers to bring their device to the market more rapidly. The first CGM sensor to receive FDA approval with the iCGM label is the Dexcom G6 device, launched in 2018 [95]. The integration of
CGM data with data of insulin pump and other wearable sensors, like activity trackers, will allow improving algorithms for glucose prediction and automatic basal insulin modulation, as recent studies with basal insulin suspension [96] and AP during exercise [97] have suggested. CGM data integrated with other diabetes management data (e.g., insulin pumps, SMBG and mHealth apps data) and activity data will also allow to enhance diabetes DSSs, enabling a better understanding of the causes driving to abnormal glucose events and, finally, a better tailoring of diabetes therapy to the patient's lifestyle and habits.

Finally as more broadly discussed in [9], CGM data could be integrated with other clinical data sources, including clinical registries, electronic health records, prescription registries and biomarkers collected in laboratory tests, which will provide important clinical contextualization to CGM data. This will allow the generation of a digital ecosystem of diabetes data that could be exploited to extract novel insights on the mechanisms of diabetes progression and develop cutting-edge data analytics for personalized diabetes management and prevention of related complications.

\section{CONFLICTS OF INTEREST}

No potential conflict of interest relevant to this article was reported.

\section{ORCID}

Giacomo Cappon https://orcid.org/0000-0003-4358-9268

Andrea Facchinetti https://orcid.org/0000-0001-8041-2280

\section{ACKNOWLEDGMENTS}

None

\section{REFERENCES}

1. Wang J. Electrochemical glucose biosensors. Chem Rev 2008; 108:814-25.

2. Acciaroli G, Vettoretti M, Facchinetti A, Sparacino G. Calibration of minimally invasive continuous glucose monitoring sensors: state-of-the-art and current perspectives. Biosensors (Basel) 2018;8:E24.

3. Clarke SF, Foster JR. A history of blood glucose meters and their role in self-monitoring of diabetes mellitus. Br J Biomed 
Sci 2012;69:83-93.

4. Cappon G, Acciaroli G, Vettoretti M, Facchinetti A, Sparacino G. Wearable continuous glucose monitoring sensors: a revolution in diabetes treatment. Electronics 2017;6:65.

5. Juvenile Diabetes Research Foundation Continuous Glucose Monitoring Study Group, Tamborlane WV, Beck RW, Bode BW, Buckingham B, Chase HP, Clemons R, Fiallo-Scharer R, Fox LA, Gilliam LK, Hirsch IB, Huang ES, Kollman C, Kowalski AJ, Laffel L, Lawrence JM, Lee J, Mauras N, O’Grady M, Ruedy KJ, Tansey M, Tsalikian E, Weinzimer S, Wilson DM, Wolpert H, Wysocki T, Xing D. Continuous glucose monitoring and intensive treatment of type 1 diabetes. N Engl J Med 2008;359:1464-76.

6. Battelino T, Conget I, Olsen B, Schutz-Fuhrmann I, Hommel E, Hoogma R, Schierloh U, Sulli N, Bolinder J; SWITCH Study Group. The use and efficacy of continuous glucose monitoring in type 1 diabetes treated with insulin pump therapy: a randomised controlled trial. Diabetologia 2012;55:3155-62.

7. Battelino T, Phillip M, Bratina N, Nimri R, Oskarsson P, Bolinder J. Effect of continuous glucose monitoring on hypoglycemia in type 1 diabetes. Diabetes Care 2011;34:795-800.

8. Facchinetti A. Continuous glucose monitoring sensors: past, present and future algorithmic challenges. Sensors (Basel) 2016; 16:E2093.

9. Vettoretti M, Cappon G, Acciaroli G, Facchinetti A, Sparacino G. Continuous glucose monitoring: current use in diabetes management and possible future applications. J Diabetes Sci Technol 2018;12:1064-71.

10. ISO: ISO 15197 (2013). In vitro diagnostic test systems: requirements for blood-glucose monitoring systems for self-testing in managing diabetes mellitus. Available from: https:// www.iso.org/obp/ui/\#iso:std:iso:15197:ed-2:v1:en (cited 2019 Jul 15).

11. Bailey TS. Clinical implications of accuracy measurements of continuous glucose sensors. Diabetes Technol Ther 2017;19: S51-4.

12. Zisser HC, Bailey TS, Schwartz S, Ratner RE, Wise J. Accuracy of the SEVEN continuous glucose monitoring system: comparison with frequently sampled venous glucose measurements. J Diabetes Sci Technol 2009;3:1146-54.

13. Weinstein RL, Schwartz SL, Brazg RL, Bugler JR, Peyser TA, McGarraugh GV. Accuracy of the 5-day FreeStyle Navigator Continuous Glucose Monitoring System: comparison with frequent laboratory reference measurements. Diabetes Care 2007;30:1125-30.
14. Bailey TS, Ahmann A, Brazg R, Christiansen M, Garg S, Watkins E, Welsh JB, Lee SW. Accuracy and acceptability of the 6-day Enlite continuous subcutaneous glucose sensor. Diabetes Technol Ther 2014;16:277-83.

15. Geoffrey M, Brazg R, Richard W. FreeStyle Navigator Continuous Glucose Monitoring System with TRUstart algorithm, a 1-hour warm-up time. J Diabetes Sci Technol 2011;5:99-106.

16. Christiansen M, Bailey T, Watkins E, Liljenquist D, Price D, Nakamura K, Boock R, Peyser T. A new-generation continuous glucose monitoring system: improved accuracy and reliability compared with a previous-generation system. Diabetes Technol Ther 2013;15:881-8.

17. Bailey TS, Chang A, Christiansen M. Clinical accuracy of a continuous glucose monitoring system with an advanced algorithm. J Diabetes Sci Technol 2015;9:209-14.

18. Bailey T, Bode BW, Christiansen MP, Klaff LJ, Alva S. The performance and usability of a factory-calibrated flash glucose monitoring system. Diabetes Technol Ther 2015;17:787-94.

19. Freestyle Libre: Abbot's Freestyle Libre. Available from: https:// www.freestylelibre.it/libre/ (cited 2019 Jul 15).

20. Dexcom Inc.: FDA authorizes marketing of the new Dexcom G6 CGM eliminating the need for fingerstick blood testing for people with diabetes. Available from: https://www.dexcom. com/news/fda-authorizes-dexcom-g6 (cited 2019 Jul 15).

21. Christiansen MP, Garg SK, Brazg R, Bode BW, Bailey TS, Slover RH, Sullivan A, Huang S, Shin J, Lee SW, Kaufman FR. Accuracy of a fourth-generation subcutaneous continuous glucose sensor. Diabetes Technol Ther 2017;19:446-56.

22. DexCom Inc. DexCom to collaborate with the life sciences team at Google on the development of breakthrough technologies to change the future of diabetes management. Available from: http://www.prnewswire.com/news-releases/dexcom-tocollaborate-with-the-life-sciences-teamat-google-on-the-development-of-breakthrough-technologies-to-change-the-futureof-diabetesmanagement-300126661.html (cited 2019 Jul 15).

23. Abbott: Abbott's FreeStyle Libre 2, with optional real-time alarms, secures CE mark for use in Europe. Available from: https://abbott.mediaroom.com/2018-10-01-Abbott-s-FreeStyle-R-Libre-2-with-Optional-Real-Time-Alarms-SecuresCE-Mark-for-Use-in-Europe (cited 2019 Jul 15).

24. Vaddiraju S, Burgess DJ, Tomazos I, Jain FC, Papadimitrakopoulos $\mathrm{F}$. Technologies for continuous glucose monitoring: current problems and future promises. J Diabetes Sci Technol 2010;4:1540-62.

25. Chen C, Zhao XL, Li ZH, Zhu ZG, Qian SH, Flewitt AJ. Cur- 
rent and emerging technology for continuous glucose monitoring. Sensors (Basel) 2017;17:E182.

26. Dehennis A, Mortellaro MA, Ioacara S. Multisite study of an implanted continuous glucose sensor over 90 days in patients with diabetes mellitus. J Diabetes Sci Technol 2015;9:951-6.

27. Gashgari H, Attallah N, Al Muallem Y, Al Dogether M, Al Moammary E, Almeshari M, Househ M. Collecting patient data from sensor-based systems: benefits and challenges. Stud Health Technol Inform 2016;226:41-4.

28. Diabetes Technology Society: DTS cybersecurity standard for connected diabetes devices. Available from: https://www.diabetestechnology.org/dtsec.shtml (cited 2019 Jul 15).

29. Hirsch IB. Glycemic variability and diabetes complications: does it matter? Of course it does! Diabetes Care 2015;38:16104.

30. Longato E, Acciaroli G, Facchinetti A, Hakaste L, Tuomi T, Maran A, Sparacino G. Glycaemic variability-based classification of impaired glucose tolerance vs. type 2 diabetes using continuous glucose monitoring data. Comput Biol Med 2018;96:141-6.

31. Danne T, Nimri R, Battelino T, Bergenstal RM, Close KL, DeVries JH, Garg S, Heinemann L, Hirsch I, Amiel SA, Beck R, Bosi E, Buckingham B, Cobelli C, Dassau E, Doyle FJ 3rd, Heller S, Hovorka R, Jia W, Jones T, Kordonouri O, Kovatchev B, Kowalski A, Laffel L, Maahs D, Murphy HR, Norgaard K, Parkin CG, Renard E, Saboo B, Scharf M, Tamborlane WV, Weinzimer SA, Phillip M. International consensus on use of continuous glucose monitoring. Diabetes Care 2017;40:1631-40.

32. International Diabetes Center: Ambulatory Glucose Profile: AGP reports. Available from: http://www.agpreport.org/agp/ agpreports (cited 2019 Jul 15).

33. Aleppo G, Ruedy KJ, Riddlesworth TD, Kruger DF, Peters AL, Hirsch I, Bergenstal RM, Toschi E, Ahmann AJ, Shah VN, Rickels MR, Bode BW, Philis-Tsimikas A, Pop-Busui R, Rodriguez H, Eyth E, Bhargava A, Kollman C, Beck RW; REPLACEBG Study Group. REPLACE-BG: a randomized trial comparing continuous glucose monitoring with and without routine blood glucose monitoring in adults with well-controlled type 1 diabetes. Diabetes Care 2017;40:538-45.

34. Aleppo G, Laffel LM, Ahmann AJ, Hirsch IB, Kruger DF, Peters A, Weinstock RS, Harris DR. A practical approach to using trend arrows on the Dexcom G5 CGM system for the management of adults with diabetes. J Endocr Soc 2017;1:1445-60.

35. Pettus J, Price DA, Edelman SV. How patients with type 1 diabetes translate continuous glucose monitoring data into diabetes management decisions. Endocr Pract 2015;21:613-20.
36. Cappon G, Marturano F, Vettoretti M, Facchinetti A, Sparacino G. In silico assessment of literature insulin bolus calculation methods accounting for glucose rate of change. J Diabetes Sci Technol 2019;13:103-10.

37. Beck RW, Tamborlane WV, Bergenstal RM, Miller KM, DuBose SN, Hall CA; T1D Exchange Clinic Network. The T1D Exchange clinic registry. J Clin Endocrinol Metab 2012;97:4383-9.

38. Tanenbaum ML, Hanes SJ, Miller KM, Naranjo D, Bensen R, Hood KK. Diabetes device use in adults with type 1 diabetes: barriers to uptake and potential intervention targets. Diabetes Care 2017;40:181-7.

39. Centers for Medicare \& Medicaid Services: CGM Rulings. Ruling No. [CMS-1682-R]. Available from: www.cms.gov/Regulationsand-Guidance/Guidance/Rulings/Downloads/CMS1682R.pdf (cited 2019 Jul 15).

40. Foster NC, Miller K, Dimeglio L, Maahs DM, Tamborlane WV, Bergenstal RM, Clements MA, Rickels MR, Smith E, Olson BA, Beck R. Marked increases in CGM use has not prevented increases in HbA1c levels in participants in the T1D Exchange (T1DX) Clinic Network. Diabetes 2018;67(Suppl 1):1689P.

41. Abbott: Abbott FreeStyle Libre 14 day flash glucose monitoring system now approved in U.S. Available from: http://abbott.mediaroom.com/2018-07-27-Abbotts-FreeStyle-R-Libre-14-DayFlash-Glucose-Monitoring-System-Now-Approved-in-U-S (cited 2019 Jul 15).

42. DeSalvo DJ, Miller KM, Hermann JM, Maahs DM, Hofer SE, Clements MA, Lilienthal E, Sherr JL, Tauschmann M, Holl RW; T1D Exchange and DPV Registries. Continuous glucose monitoring and glycemic control among youth with type 1 diabetes: international comparison from the T1D Exchange and DPV Initiative. Pediatr Diabetes 2018;19:1271-5.

43. Heinemann L, Stuhr A, Brown A, Freckmann G, Breton MD, Russell S, Heinemann L. Self-measurement of blood glucose and continuous glucose monitoring: is there only one future? Eur Endocrinol 2018;14:24-9.

44. American Diabetes Association. 7. Diabetes technology: standards of medical care in diabetes. 2019. Diabetes Care 2019;42 (Suppl 1):S71-80.

45. Bailey TS, Grunberger G, Bode BW, Handelsman Y, Hirsch IB, Jovanovic L, Roberts VL, Rodbard D, Tamborlane WV, Walsh J; American Association of Clinical Endocrinologists (AACE); American College of Endocrinology (ACE). American Association of Clinical Endocrinologists and American College of Endocrinology 2016 outpatient glucose monitoring consensus statement. Endocr Pract 2016;22:231-61. 
46. Peters AL, Ahmann AJ, Battelino T, Evert A, Hirsch IB, Murad $\mathrm{MH}$, Winter WE, Wolpert $\mathrm{H}$. Diabetes technology-continuous subcutaneous insulin infusion therapy and continuous glucose monitoring in adults: an Endocrine Society clinical practice guideline. J Clin Endocrinol Metab 2016;101:3922-37.

47. Jovanovic L. The role of continuous glucose monitoring in gestational diabetes mellitus. Diabetes Technol Ther 2000;2 Suppl 1:S67-71.

48. Yu F, Lv L, Liang Z, Wang Y, Wen J, Lin X, Zhou Y, Mai C, Niu J. Continuous glucose monitoring effects on maternal glycemic control and pregnancy outcomes in patients with gestational diabetes mellitus: a prospective cohort study. J Clin Endocrinol Metab 2014;99:4674-82.

49. Rodbard D. Continuous glucose monitoring: a review of recent studies demonstrating improved glycemic outcomes. Diabetes Technol Ther 2017;19:S25-37.

50. Bergenstal RM, Klonoff DC, Garg SK, Bode BW, Meredith M, Slover RH, Ahmann AJ, Welsh JB, Lee SW, Kaufman FR; ASPIRE In-Home Study Group. Threshold-based insulin-pump interruption for reduction of hypoglycemia. N Engl J Med 2013;369:224-32.

51. Bergenstal RM, Tamborlane WV, Ahmann A, Buse JB, Dailey G, Davis SN, Joyce C, Peoples T, Perkins BA, Welsh JB, Willi SM, Wood MA; STAR 3 Study Group. Effectiveness of sensoraugmented insulin-pump therapy in type 1 diabetes. $\mathrm{N}$ Engl J Med 2010;363:311-20.

52. ClinicalTrials.gov: An evaluation of novel glucose sensing technology on hypoglycemia in type 1 diabetes (IMPACT). Available from: https://clinicaltrials.gov/ct2/show/NCT02232698 (cited 2019 Jul 15).

53. Haak T, Hanaire H, Ajjan R, Hermanns N, Riveline JP, Rayman G. Flash glucose-sensing technology as a replacement for blood glucose monitoring for the management of insulintreated type 2 diabetes: a multicenter, open-label randomized controlled trial. Diabetes Ther 2017;8:55-73.

54. Hermanns N, Ehrmann D, Schipfer M, Kroger J, Haak T, Kulzer B. The impact of a structured education and treatment programme (FLASH) for people with diabetes using a flash sensor-based glucose monitoring system: results of a randomized controlled trial. Diabetes Res Clin Pract 2019;150:111-21.

55. Monnier L, Colette C, Wojtusciszyn A, Dejager S, Renard E, Molinari N, Owens DR. Toward defining the threshold between low and high glucose variability in diabetes. Diabetes Care 2017;40:832-8.

56. Jamiolkowska M, Jamiolkowska I, Luczynski W, Tolwinska J,
Bossowski A, Glowinska Olszewska B. Impact of real-time continuous glucose monitoring use on glucose variability and endothelial function in adolescents with type 1 diabetes: new technology. New possibility to decrease cardiovascular risk? J Diabetes Res 2016;2016:4385312.

57. Tumminia A, Crimi S, Sciacca L, Buscema M, Frittitta L, Squatrito S, Vigneri R, Tomaselli L. Efficacy of real-time continuous glucose monitoring on glycaemic control and glucose variability in type 1 diabetic patients treated with either insulin pumps or multiple insulin injection therapy: a randomized controlled crossover trial. Diabetes Metab Res Rev 2015;31:61-8.

58. O’Connor PJ, Sperl-Hillen JM, Fazio CJ, Averbeck BM, Rank $\mathrm{BH}$, Margolis KL. Outpatient diabetes clinical decision support: current status and future directions. Diabet Med 2016;33: 734-41.

59. Jia P, Zhao P, Chen J, Zhang M. Evaluation of clinical decision support systems for diabetes care: an overview of current evidence. J Eval Clin Pract 2019;25:66-77.

60. Cappon G, Vettoretti M, Marturano F, Facchinetti A, Sparacino G. A neural-network-based approach to personalize insulin bolus calculation using continuous glucose monitoring. J Diabetes Sci Technol 2018;12:265-72.

61. Breton MD, Patek SD, Lv D, Schertz E, Robic J, Pinnata J, Kollar L, Barnett C, Wakeman C, Oliveri M, Fabris C, Chernavvsky D, Kovatchev BP, Anderson SM. Continuous glucose monitoring and insulin informed advisory system with automated titration and dosing of insulin reduces glucose variability in type 1 diabetes mellitus. Diabetes Technol Ther 2018;20:531-40.

62. DreaMed Diabeted Ltd.: On DreaMed Advisor Pro. Available from: https://dreamed-diabetes.com/ (cited 2019 Jul 15).

63. PR Newswire Association: DreaMed diabetes granted FDA authorization to market advisor pro, offering personalized optimization of insulin pump therapy. Available from: https://www. prnewswire.com/news-releases/dreamed-diabetes-grantedfda-authorization-to-market-advisor-pro-offering-personalized-optimization-of-insulin-pump-therapy-300667617.html (cited 2019 Jul 15).

64. Herrero P, Lopez B, Martin C. PEPPER: Patient empowerment through predictive personalized decision support. Proceedings of 1st Workshop on Artificial Intelligence for Diabetes (ECAI); 2016 Aug 30; Hague, NL. ECAI; 2016. p8-9.

65. Agrawal P, Welsh JB, Kannard B, Askari S, Yang Q, Kaufman FR. Usage and effectiveness of the low glucose suspend feature of the Medtronic Paradigm Veo insulin pump. J Diabetes Sci Technol 2011;5:1137-41. 
66. Zhong A, Choudhary P, McMahon C, Agrawal P, Welsh JB, Cordero TL, Kaufman FR. Effectiveness of automated insulin management features of the MiniMed( $($ ) $640 \mathrm{G}$ sensor-augmented insulin pump. Diabetes Technol Ther 2016;18:657-63.

67. Buckingham BA, Cameron F, Calhoun P, Maahs DM, Wilson DM, Chase HP, Bequette BW, Lum J, Sibayan J, Beck RW, Kollman C. Outpatient safety assessment of an in-home predictive low-glucose suspend system with type 1 diabetes subjects at elevated risk of nocturnal hypoglycemia. Diabetes Technol Ther 2013;15:622-7.

68. Hughes CS, Patek SD, Breton MD, Kovatchev BP. Hypoglycemia prevention via pump attenuation and red-yellow-green "traffic" lights using continuous glucose monitoring and insulin pump data. J Diabetes Sci Technol 2010;4:1146-55.

69. Buckingham B, Chase HP, Dassau E, Cobry E, Clinton P, Gage V, Caswell K, Wilkinson J, Cameron F, Lee H, Bequette BW, Doyle FJ 3rd. Prevention of nocturnal hypoglycemia using predictive alarm algorithms and insulin pump suspension. Diabetes Care 2010;33:1013-7.

70. Cameron F, Wilson DM, Buckingham BA, Arzumanyan H, Clinton P, Chase HP, Lum J, Maahs DM, Calhoun PM, Bequette BW. Inpatient studies of a Kalman-filter-based predictive pump shutoff algorithm. J Diabetes Sci Technol 2012;6: $1142-7$.

71. Abraham MB, de Bock M, Paramalingam N, O’Grady MJ, Ly TT, George C, Roy A, Spital G, Karula S, Heels K, Gebert R, Fairchild JM, King BR, Ambler GR, Cameron F, Davis EA, Jones TW. Prevention of insulin-induced hypoglycemia in type 1 diabetes with predictive low glucose management system. Diabetes Technol Ther 2016;18:436-43.

72. Buckingham BA, Bailey TS, Christiansen M, Garg S, Weinzimer S, Bode B, Anderson SM, Brazg R, Ly TT, Kaufman FR. Evaluation of a predictive low-glucose management system inclinic. Diabetes Technol Ther 2017;19:288-92.

73. Choudhary P, Olsen BS, Conget I, Welsh JB, Vorrink L, Shin JJ. Hypoglycemia prevention and user acceptance of an insulin pump system with predictive low glucose management. Diabetes Technol Ther 2016;18:288-91.

74. Battelino T, Nimri R, Dovc K, Phillip M, Bratina N. Prevention of hypoglycemia with predictive low glucose insulin suspension in children with type 1 diabetes: a randomized controlled trial. Diabetes Care 2017;40:764-70.

75. Abraham MB, Nicholas JA, Smith GJ, Fairchild JM, King BR, Ambler GR, Cameron FJ, Davis EA, Jones TW; PLGM Study Group. Reduction in hypoglycemia with the predictive low- glucose management system: a long-term randomized controlled trial in adolescents with type 1 diabetes. Diabetes Care 2018;41:303-10.

76. Vettoretti M, Facchinetti A. Combining continuous glucose monitoring and insulin pumps to automatically tune the basal insulin infusion in diabetes therapy: a review. Biomed Eng Online 2019;18:37.

77. Thabit H, Hovorka R. Coming of age: the artificial pancreas for type 1 diabetes. Diabetologia 2016;59:1795-805.

78. Dadlani V, Pinsker JE, Dassau E, Kudva YC. Advances in closed-loop insulin delivery systems in patients with type 1 diabetes. Curr Diab Rep 2018;18:88.

79. Bertachi A, Ramkissoon CM, Bondia J, Vehi J. Automated blood glucose control in type 1 diabetes: a review of progress and challenges. Endocrinol Diabetes Nutr 2018;65:172-81.

80. Steil GM, Rebrin K, Darwin C, Hariri F, Saad MF. Feasibility of automating insulin delivery for the treatment of type 1 diabetes. Diabetes 2006;55:3344-50.

81. Weinzimer SA, Steil GM, Swan KL, Dziura J, Kurtz N, Tamborlane WV. Fully automated closed-loop insulin delivery versus semiautomated hybrid control in pediatric patients with type 1 diabetes using an artificial pancreas. Diabetes Care 2008;31: 934-9.

82. Kropff J, Del Favero S, Place J, Toffanin C, Visentin R, Monaro M, Messori M, Di Palma F, Lanzola G, Farret A, Boscari F, Galasso S, Magni P, Avogaro A, Keith-Hynes P, Kovatchev BP, Bruttomesso D, Cobelli C, DeVries JH, Renard E, Magni L; AP@home consortium. 2 Month evening and night closedloop glucose control in patients with type 1 diabetes under free-living conditions: a randomised crossover trial. Lancet Diabetes Endocrinol 2015;3:939-47.

83. Atlas E, Nimri R, Miller S, Grunberg EA, Phillip M. MD-logic artificial pancreas system: a pilot study in adults with type $1 \mathrm{di}-$ abetes. Diabetes Care 2010;33:1072-6.

84. Stone MP, Agrawal P, Chen X, Liu M, Shin J, Cordero TL, Kaufman FR. Retrospective analysis of 3-month real-world glucose data after the MiniMed 670G system commercial launch. Diabetes Technol Ther 2018;20:689-92.

85. Cameron FM, Ly TT, Buckingham BA, Maahs DM, Forlenza GP, Levy CJ, Lam D, Clinton P, Messer LH, Westfall E, Levister C, Xie YY, Baysal N, Howsmon D, Patek SD, Bequette BW. Closed-loop control without meal announcement in type 1 diabetes. Diabetes Technol Ther 2017;19:527-32.

86. Boughton CK, Bally L, Martignoni F, Hartnell S, Herzig D, Vogt A, Wertli MM, Wilinska ME, Evans ML, Coll AP, Stettler C, 
Hovorka R. Fully closed-loop insulin delivery in inpatients receiving nutritional support: a two-centre, open-label, randomised controlled trial. Lancet Diabetes Endocrinol 2019;7: 368-77.

87. Bally L, Thabit H, Hartnell S, Andereggen E, Ruan Y, Wilinska ME, Evans ML, Wertli MM, Coll AP, Stettler C, Hovorka R. Closed-loop insulin delivery for glycemic control in noncritical care. N Engl J Med 2018;379:547-56.

88. Taleb N, Carpentier AC, Messier V, Ladouceur M, Haidar A, Rabasa-Lhoret R. Efficacy of artificial pancreas use in patients with type 2 diabetes using intensive insulin therapy: a randomized crossover pilot trial. Diabetes Care 2019;42:e107-9.

89. Peters TM, Haidar A. Dual-hormone artificial pancreas: benefits and limitations compared with single-hormone systems. Diabet Med 2018;35:450-9.

90. Lewis D, Leibrand S; \#OpenAPS Community. Real-world use of open source artificial pancreas systems. J Diabetes Sci Technol 2016;10:1411.

91. Litchman ML, Lewis D, Kelly LA, Gee PM. Twitter analysis of \#OpenAPS DIY artificial pancreas technology use suggests improved A1C and quality of life. J Diabetes Sci Technol 2019; 13:164-70.

92. Medtronic: Medtronic and Qualcomm collaborate to aim to improve care and health outcomes for people with type 2 diabetes. Available from: http://newsroom.medtronic.com/phoenix.zhtml? $c=251324 \& \mathrm{p}=$ irolnewsArticle\&ID=2172203 (cited 2019 Jul 15).

93. SugarBEAT®: SugarBEAT 2017. Available from: http://sugarbeat.com (cited 2019 Jul 15).

94. LifePlus: LifePlus Inc. Available from: https://www.lifeplusinc. net (cited 2019 Jul 15).

95. U.S. Food \& Drug Administration: FDA authorizes first fully interoperable continuous glucose monitoring system, streamlines review pathway for similar devices. Available from: https://www.fda.gov/news-events/press-announcements/fdaauthorizes-first-fully-interoperable-continuous-glucose-monitoring-system-streamlines-review (cited 2019 Jul 15).

96. Stenerson M, Cameron F, Wilson DM, Harris B, Payne S, Bequette BW, Buckingham BA. The impact of accelerometer and heart rate data on hypoglycemia mitigation in type 1 diabetes. J Diabetes Sci Technol 2014;8:64-9.

97. DeBoer MD, Chernavvsky DR, Topchyan K, Kovatchev BP, Francis GL, Breton MD. Heart rate informed artificial pancreas system enhances glycemic control during exercise in adolescents with T1D. Pediatr Diabetes 2017;18:540-6. 